\title{
Faktor-Faktor yang mempengaruhi Penyerapan Tenaga Kerja pada Sektor UMKM di Indonesia: Pendekatan Error Correction Model
}

\author{
Factors affecting Labor Absorption on the MSME Sector \\ in Indonesia: Error Correction Model Approach
}

\author{
A. Azhari \\ Fakultas Ekonomi dan Bisnis, Universitas Islam Kebangsaan Indonesia, Bireuen \\ e-mail korespondensi: azharikuliah@gmail.com
}

\begin{tabular}{|c|c|}
\hline Info $\mathrm{A}$ & \multirow{3}{*}{$\begin{array}{l}\text { Abstrak } \\
\text { Penelitian ini bertujuan untuk menguji hubungan jangka pendek dan jangka } \\
\text { panjang sektor UMKM terhadap penyerapan tenaga kerja di Indonesia. Metode } \\
\text { yang dipakai adalah error correction model (ECM). Variabel terdiri dari jumlah } \\
\text { unit UMKM, PDB dan investasi sebagai variabel independen, dan tenaga kerja } \\
\text { UMKM sebagai variabel dependen. Data yang digunakan dari tahun } 1996 \\
\text { sampai 2018. Hasil penelitian menunjukkan bahwa dalam jangka pendek jumlah } \\
\text { UMKM dan PDB mempunyai pengaruh yang signifikan terhadap penyerapan } \\
\text { tenaga kerja di Indonesia; sedangkan hanya jumlah unit UMKM yang } \\
\text { berpengaruh terhadap penyerapan tenaga kerja sektor UMKM di Indonesia } \\
\text { dalam jangka panjang. UMKM diharapkan meningkatkan kapasitasnya dalam } \\
\text { hal pengelolaan bisnis. Bagi pemangku kebijakan dan stakeholder lainnya agar } \\
\text { dapat membuat program dalam upaya meningkatkan jumlah UMKM serta } \\
\text { menciptakan iklim usaha yang kondusif bagi pelaku UMKM di Indonesia. } \\
\text { Kata Kunci: UMKM, Product Domestic Bruto, Investasi, Error Correction } \\
\text { Model. }\end{array}$} \\
\hline $\begin{array}{l}\text { Riwayat Artikel : } \\
\text { Diterima: } 23 \text { Juni } 2020 \\
\text { Disetujui: } 26 \text { Agustus } 2020 \\
\text { Dipublikasikan: Januari } 2021\end{array}$ & \\
\hline $\begin{array}{l}\text { Nomor DOI } \\
\text { 10.33059/jseb.v12i1.2435 } \\
\text { Cara Mensitasi : } \\
\text { Azhari, A. (2021). Faktor- } \\
\text { Faktor yang mempengaruhi } \\
\text { penyerapan tenaga kerja pada } \\
\text { sektor UMKM di Indonesia: } \\
\text { Pendekatan error correction } \\
\text { model. Jurnal Samudra } \\
\text { Ekonomi dan Bisnis, 12(1), } \\
\text { 76-88. doi: 10.33059/jseb. } \\
\text { v12i1.2435. }\end{array}$ & \\
\hline & \multirow{3}{*}{$\begin{array}{l}\text { Abstract } \\
\text { The research aims to examine the short-term and long-term relationship of the } \\
\text { MSMEs sector toward absorption employment in Indonesia. The method used } \\
\text { is error correction model (ECM). The variables consisted of the number of } \\
\text { MSMEs units, GDP and investment as independent variables, and MSME labor } \\
\text { as the dependent variable. The data is used from } 1996 \text { to 2018. The results } \\
\text { show that in the short term the number of MSMEs and GDP has a significant } \\
\text { effect on employment in Indonesia; whereas only the number of MSMEs units } \\
\text { will affect the employment of the MSME sector in Indonesia in the long run,. } \\
\text { MSMEs are expected to increase their capacity in terms of business } \\
\text { management. For policymakers and other stakeholders should to create } \\
\text { programs in effort to increase the number of MSMEs as well as creating a } \\
\text { conducive business climate for MSMEs players in Indonesia. } \\
\text { Keywords: MSMEs, Product Domestic Bruto, Investment, Error Correction } \\
\text { Model. }\end{array}$} \\
\hline & \\
\hline $\begin{array}{l}\text { DOI Number: } \\
\text { 10.33059/jseb.v12i1.2435 } \\
\text { How to cite : } \\
\text { Azhari, A. (2021). Faktor- } \\
\text { Faktor yang mempengaruhi } \\
\text { penyerapan tenaga kerja pada } \\
\text { sektor UMKM di Indonesia: } \\
\text { Pendekatan } \text { error correction } \\
\text { model. Jurnal Samudra } \\
\text { Ekonomi dan Bisnis, } 12(1) \text {, } \\
\text { 76-88. doi: } 10.33059 / \text { jseb. } \\
\text { v12i1.2435. }\end{array}$ & \\
\hline
\end{tabular}




\section{PENDAHULUAN}

Jumlah total usaha mikro kecil dan menengah (UMKM) di Indonesia mencapai 64.194.057 unit (Kemenkop dan UKM RI, 2019). Terdapat beberapa faktor yang menyebabkan UMKM dapat tumbuh secara signifikan, diantaranya tidak memerlukan banyak modal untuk memulai usaha, tingkat teknologi yang sederhana, fleksibel dalam menyesuaikan diri atas pasar, dan mampu menciptakan lapangan kerja baru (Abor \& Quartey, 2010; Saleh \& Ndubisi, 2006). Pada akhir tahun 2018 jumlah tenaga kerja sektor UMKM yang mampu diserap sebanyak 116.978.631 orang (Kemenkop dan UKM RI, 2019). Jika melihat data kependudukan Indonesia mencapai 271 juta orang (BPS, 2020), maka $43 \%$ penduduk Indonesia telah bekerja pada sektor UMKM. Dengan jumlah UMKM yang begitu besar, tentunya banyak menyerap tenaga kerja di Indonesia. Namun demikian, UMKM masih mengalami kendala seperti rendahnya sumber daya manusia, pemasaran produk dan manajemen yang masih tradisional (Abor \& Quartey, 2010; Riani, 2011).

Pada masa krisis tahun 1997 dan 2007 di Indonesia, sektor UMKM ternyata dapat survive apabila dibandingkan dengan usaha lainnya, yang akhirnya menjadi tumpuan bagi perekonomian secara nasional (Budiarto et al., 2018). Banyak alasan yang menyebabkan jumlah UMKM di Indonesia meningkat. Pertama, produksi barang dan jasa yang dihasilkan UMKM umumnya berpendapatan rendah. Kedua, sektor UMKM umumnya menggunakan modal sendiri ataupun tidak memperoleh dana pihak perbankan, sehingga ketika terjadi crisis tidak berimbas dengan kenaikan suku bunga. Ketiga, adanya krisis menyebabkan banyak usaha sektor formal yang memberhentikan pekerjanya, sehingga memaksa pekerja yang terkena PHK akan berusaha di sektor informal (Suci, 2017; As'har, 2015; Syuhada et al., 2014).

Dari segi product domestic bruto (PDB), setiap tahunnya kontribusi UKKM terhadap PDB mengalami peningkatan. Pada akhir tahun 2018, total PDB yang dihasilkan UMKM dan Usaha Besar mencapai Rp. 9.995,3 triliun (Kemenkop dan UKM RI, 2019). Dari angka tersebut sektor UMKM mampu menyumbang Rp. 5.721,1 triliun bagi pertumbuhan ekonomi Indonesia. Dengan kata lain, 57\% PDB Indonesia kontribusinya bersumber dari sektor UMKM dan selebihnya dari usaha besar. Begitu juga halnya dari faktor investasi yang dimiliki sektor UMKM di Indonesia, setiap tahunnya mengalami penambahan yang signifikan (BPS, 2020). Pada akhir 2018, investasi pada sektor UMKM sebesar Rp. 1.675.1 triliun, sedangkan investasi usaha besar Rp. 1.317,9 triliun.

Meskipun UMKM mempunyai potensi yang begitu banyak untuk pembangunan ekonomi secara nasional, dalam kenyataannya sektor UMKM masih memiliki kelemahan. Kelemahan ini bersifat internal dan eksternal, seperti sumber daya manusia, pemasaran, permodalan, iklim usaha dan penguasaan teknologi yang belum optimal. Dalam upaya mengatasi berbagai kelemahan UMKM itu diperlukan upaya untuk meningkatkan daya saing. Hal ini dilandasi dengan berbagai alasan, salah satunya sektor UMKM mampu menyerap tenaga kerja yang banyak di Indonesia. Jumlah UMKM yang banyak akan mempengaruhi daya serap atas tenaga kerja (Widdyantoro, 2014; Setiawan, 2010).

Beberapa penelitian yang telah dilakukan mengenai variabel-variabel yang dapat mempengaruhi penyerapan tenaga kerja pada sektor UMKM di Indonesia. Namun demikian sepengetahuan peneliti bahwa penelitian yang dilakukan hanya menganalisis menggunakan model regresi berganda, tanpa melihat pola hubungan jangka pendek antara variabel. 
Seperti penelitian yang dilakukan Mulyadi et al. (2018) yang menganalisis variabel yang dapat menyebakan serapan tenaga kerja pada small industry di Muaro propinsi Jambi. Penelitian yang dilakukan Bustam (2016) yang menganalisis daya serap tenaga kerja pada UMKM di Indonesia. Selanjutnya pengujian yang dilakukan oleh Widdyantoro (2013) menguji faktor yang mempengaruhi penyerapan tenaga kerja pada sektor UMKM di Indonesia dengan analisis regresi berganda. Begitu juga penelitian kinerja UMKM di Kota Semarang yang diteliti oleh Setiawan (2010). Berikutnya, analisis keterkaitan minimum wage terhadap daya serap tenaga kerja di Indonesia (Sulistiawati, 2012).

Penelitian ini bertujuan menganalisis peranan sektor UKM terhadap penyerapan tenaga kerja di Indonesia. Peneliti menggunakan variabel-variabel PDB, investasi, jumlah unit UMKM dan tenaga kerja sektor UMKM dalam jangka pendek dan jangka panjang. Dengan upaya itu, penelitian ini dapat memberikan saran dan bahan masukan bagi pembuat kebijakan dalam mengembangkan sektor UMKM di Indonesia.

\section{UMKM}

Menurut Undang-Undang No. 20 Tahun 2008 tentang Usaha Mikro, Kecil dan Menengah mempunyai tujuan menumbuhkan dan mengembangkan usahanya dalam rangka membangun perekonomian nasional berdasarkan demokasi ekonomi yang berkeadilan bagi UMKM. Ada beberapa kriteria sebuah unit bisnis untuk dapat dikategorikan ke dalam usaha mikro, kecil maupun menengah.

Setidaknya ada dua syarat yang dimiliki unit bisnis agar dapat dikategorikan usaha skala mikro, kecil maupun menengah, yaitu kekayaan bersih dan jumlah penjualan. Untuk kelompok usaha mikro mempunyai kekayaan bersih paling maksimal Rp. 50 juta (non tanah dan bangunan) dengan penjualan paling tinggi sebesar Rp. 300 juta per tahunnya.

Selanjutnya untuk usaha kecil, memiliki omset penjualan maksimal Rp. 2.,5 milyar tiap tahun dengan jumla aset paling banyak Rp. 500 juta. Terakhir, kelompok usaha menengah mempunyai syarat maksimal kekayaan tidak termasuk bangunan dan tanah sebanyak Rp. 10 milyar dan hasil penjualan per tahunnya maksimal Rp. 50 milyar (UU No. 20 Tahun 2008).

\section{Product Domestic Bruto}

Product domestic bruto merupakan menjadi indikator yang sering dipakai untuk mengukur tingkat keberhasilan pada sebuah negara. Produk Domestik Bruto (PDB) adalah total nilai barang dan jasa yang diproduksi di dalam negara yang bersangkutan untuk kurun waktu tertentu. Interpretasi dari pernyataan tersebut mengindikasikan bahwa yang akan dihitung dalam kategori GDP adalah produk atau output yang berupa barang dan jasa dalam suatu perekonomian yang diproduksi oleh input atau faktor-faktor produksi yang dimiliki oleh warga negara yang bersangkutan maupun oleh warga negara asing yang tinggal secara geografis di negara itu (Sunyoto et al., 2014).

PDB adalah salah satu indikator yang penting untuk mengetahui tren perkembangan perekonomian pada sebuah negara dalam periode tertentu, apakah atas dasar harga berlaku atau atas dasar harga konstan (BI, 2016). Selain itu, Bank Indonesia memaparkan bahwa PDB menurut lapangan usaha dikelompokkan dalam 17 lapangan usaha sesuai dengan KBLI 2009 dan KBKI 2010. Sedangkan berdasarkan penggunaannya, PDB dikelompokkan ke dalam tujuh komponen.

Pertama adalah pengeluaran konsumsi rumah tangga, mencakup semua pengeluaran untuk konsumsi barang dan jasa dikurangi dengan penjualan neto barang bekas dan sisa 
yang dilakukan rumah tangga selama periode tertentu (triwulan dan atau setahun). Kedua adalah pengeluaran lembaga nonprofit yang melayani rumah tangga, mencakup kegiatan dan pengeluaran yang dilakukan oleh lembaga nirlaba yang konsentrasi konsumennya adalah rumah tangga, seperti yayasan dan lainnya.

Ketiga adalah pengeluaran konsumsi pemerintah, mencakup pengeluaran untuk belanja pegawai, penyusutan dan belanja barang, baik pemerintah pusat dan daerah, tidak termasuk penerimaan dari produksi barang dan jasa yang dihasilkan; dimana data yang dipakai adalah realisasi APBN. Keempat adalah membentuk modal tetap domestik bruto, seperti pembuatan dan pembelian barang modal baru dari dalam negeri dan dari luar negeri; dimana metode yang dipakai adalah pendekatan arus barang. Kelima yaitu perubahan inventori, dimana perubahan stok dihitung dari PDB hasil penjumlahan nilai tambah bruto sektoral dikurangi komponen permintaan akhir lainnya. Keenam yaitu ekspor barang dan jasa; dimana ekspor barang dinilai menurut harga free on board (fob). Ketujuh adalah impor barang dan jasa, dimana impor barang dinilai menurut cost insurance freight (cif).

\section{Investasi}

Investasi bertujuan untuk menambah tingkat produksi agar maksimal yang pada akhirnya menghasilkan output atau surplus yang lebih besar. Dengan demikian, peluang atau kesempatan kerja akan meningkat dalam rangka penyerapan tenaga kerja. Dalam teori Harrod-Domar dijelaskan bahwa di dalam jangka panjang, faktor investasi mempunyai pengaruh ganda. Pengaruh pertama bahwa investasi akan mempengaruhi permintaan agregat; dan pengaruh kedua bahwa unsur investasi juga dapat mempengaruhi kapasitas produksi secara nasional dengan cara menambah stok modal (Nizar et al., 2013).
Raselawati (2011) dalam kajiannya menyatakan bahwa modal yang dikeluarkan untuk satu atau lebih asset yang dimiliki umumnya jangka panjang dengan harapan mendapat gain di masa yang akan datang sebagai kompensasi secara professional atas penundaan konsumsi, dampak inflasi dan resiko yang ditanggung. Menurut Kemenkop dan UKM RI (2019), investasi adalah suatu kegiatan penanaman modal pada berbagai kegiatan (produksi) dengan harapan untuk memperoleh keuntungan (gain/benefit) di masa-masa yang akan datang.

Investasi pada sektor UMKM dari tahun ke tahun memiliki nilai yang positif. Ini di tandai dengan meningkatnya nilai investasi pada sektor tersebut (Kemenkop dan UKM RI, 2019; Tyas \& Safitri, 2014; Sukesti \& Iriyanto, 2011). Investasi dapat dibagi kepada dua kategori, yaitu investasi asing dan investasi domestik. Biasanya investasi asing dipengaruhi perusahaan maupun pemerintah dari luar negeri (PMA); sedangkan investasi swasta lebih dipengaruhi oleh pihak swasta dan pemerintah dalam negeri (PMD) (Jened, 2016).

\section{Error Correction Model}

Error correction model (ECM) merupakan salah satu metode untuk menghindari regresi lancung pada model linear dinamik (Gujarati, 2014). Error correction model atau model koreksi kesalahan adalah teknik yang digunakan untuk mengoreksi kondisi ketidakseimbangan jangka pendek menuju posisi keseimbangan dalam jangka panjang. ECM juga dapat menjelaskan hubungan peubah variabel dependent dengan peubah variabel independent pada waktu sekarang maupun sebelumnya.

Widarjono (2013) menjelaskan bahwa metode error correction model (ECM) pertama sekali dipopulerkan oleh EngleGranger. Ada beberapa keunggulan dalam 
ECM. Keunggulan yang paling menonjol adalah ECM mampu mengatasi masalah yang terdapat pada data penelitian time series yang tidak stationer dan regresi lancung. Misalkan terdapat hubungan jangka panjang pada dua buah variabel X dan Y (Widarjono, 2013):

$$
\mathrm{Yt}=\beta_{0}+\beta_{1} \mathrm{X}_{\mathrm{t}}
$$

Jika variabel $\mathrm{Y}$ pada titik keseimbagan terhdap $\mathrm{X}$, maka keseimbangan variabel $\mathrm{X}$ dan $\mathrm{Y}$ pada persamaan pertama terpenuhi. Namun demikian, dalam variabel-variabel perekonomian jarang ditemukan di dalam sebuah keseimbangan. Ketika $Y_{t}$ mempunyai nilai yang berbeda dengan keseimbangannya, maka nilai perbedaan yang terjadi pada $\mathrm{X}$ dan Y dalam persamaan pertama adalah:

$$
\mathrm{C}_{\mathrm{t}}=\mathrm{Y}_{\mathrm{t}}-\beta_{0}-\beta_{1} \mathrm{X}_{\mathrm{t}}
$$

Nilai $\mathrm{EC}_{\mathrm{t}}$ ini disebut sebagai kesalahan pada titik ketidakseimbangan (disequilibrium error). Dengan demikian, apabila $\mathrm{EC}_{\mathrm{t}}=0$, maka variabel $\mathrm{Y}$ dan $\mathrm{X}$ akan mengalami keseimbangan. Oleh karena variabel $\mathrm{X}$ dan $\mathrm{Y}$ jarang ditemukan keseimbangan. Solusinya adalah melakukan observasi atas hubungan ketidakeseimbangan (jangka pendek), dengan cara unsur kelambanan variabel $\mathrm{Y}$ dan $\mathrm{X}$.

Menurut Engle-Granger, jika variabel Y dan $\mathrm{X}$ tidak stationer, akan tetapi terkointegrasi, maka hubungan $\mathrm{X}$ dan $\mathrm{Y}$ dapat dijelaskan dengan ECM. Persamaannya yaitu:

$$
\mathrm{DY}_{\mathrm{t}}=\alpha_{0}+\alpha_{1} \mathrm{DX}_{\mathrm{t}}+\alpha_{2} \mathrm{EC}_{\mathrm{t}}+\varepsilon_{\mathrm{t}}
$$

dimana $\mathrm{EC}_{\mathrm{t}}=\mathrm{Y}_{\mathrm{t}}-\beta_{0}-\beta_{1} \mathrm{X}_{\mathrm{t}} \cdot \alpha_{1}$ merupakan koefisien jangka pendek, sedangkan $\beta_{1}$ dalam persamaan dua merupakan koefisien jangka panjang. Selanjutnya, $\alpha_{2}$ adalah nilai mutlak yang menjelaskan seberapa cepat waktu dibutuhkan agar mencapai nilai keseimbangan.

\section{METODE PENELITIAN}

Penelitian ini menganalisis variabel yang mempengaruhi daya serap tenaga kerja pada sektor UMKM di Indonesia yang menggunakan metode analisis error correction model. Hal inilah yang membedakan dengan penelitian sebelumnya yang menggunakan alat analisis berganda tanpa jangka pendek antara variabel independen dengan variabel dependen. Data yang digunakan adalah data time series dari tahun 1996 sampai 2018. Data diperoleh dari Kementerian Koperasi dan UKM Republik Indonesia dan BPS, yaitu jumlah UMKM, investasi, product dometic bruto, dan tenaga kerja pada sektor UMKM.

Metode analisis data dalam penelitian ini menggunakan beberapa langkah, yaitu: (1) membuat deskriptif dari masing-masing variabel; (2) melakukan uji stasioneritas terhadap variabel independen dan dependen; (3) pengujian derajat integrasi; (4) pengujian kointegrasi; (5) analisis estimasi ECM; dan (6) interpretasi dari hasil estimasi. Selain itu, pada penelitian ini juga menggunakan uji asumsi klasik yang meliputi uji normalitas, uji multikolineritas, uji autokorelasi, dan uji heteroskedastisitas.

Adapun estimasi yang digunakan dalam penelitian ini menggunakan error correction model yang dikembangkan Engle-Granger. Estimasi model yang digunakan dari metode ECM baik untuk jangka pendek dan jangka panjang dijelaskan sebagai berikut.

Analisis regresi linier berganda untuk jangka pendek menggunakan model:

$$
\begin{aligned}
\text { DTK }_{t}= & \alpha_{0}+\alpha_{1} \text { DPDB }_{t}+\alpha_{2} \text { DJU }_{t}+ \\
& \alpha_{3} \operatorname{DInv}_{t}+\alpha_{4} \text { PDB }_{t-1}+\alpha_{5} \mathrm{JU}_{\mathrm{t}-1} \\
& +\alpha_{6} \mathrm{Inv}_{\mathrm{t}-1}+\alpha_{7} \mathrm{ECT}
\end{aligned}
$$

atau,

$$
\begin{aligned}
\text { DTK }_{t}= & \alpha_{0}+\alpha_{1} \text { DPDB }+\alpha_{2} \text { DJU }_{t}+ \\
& \alpha_{3} \text { DInv }_{t}+\alpha_{4} \text { BPDB }+\alpha_{5} \text { BJU } \\
& +\alpha_{6} \text { BInv }+\alpha_{7} \text { ECT }
\end{aligned}
$$

dimana D adalah difference pertama, B adalah kelambanan ke belakang (backward lag operator), TK merupakan penyerapan tenaga kerja, PDB adalah product domestic bruto, JU 
adalah jumlah unit UMKM, dan Inv adalah investasi sektor UMKM. CT merupakan error correction, dengan formula:

$$
\begin{aligned}
\mathrm{CT}= & \alpha_{7}\left(\alpha_{4} \mathrm{PDB}_{\mathrm{t}-1}+\alpha_{5} \mathrm{JU}_{\mathrm{t}-1}+\alpha_{6} \operatorname{Inv}_{\mathrm{t}-1}\right. \\
& \left.-\mathrm{TK}_{\mathrm{t}-1}\right)
\end{aligned}
$$

Berikutnya, model analisis regresi linier berganda untuk jangka panjang adalah:

$$
\mathrm{TK}_{\mathrm{t}}=\mathrm{C}+\beta_{1} \mathrm{PDB}+\beta_{2} \mathrm{JU}+\beta_{3} \operatorname{Inv}+\mathrm{e}_{\mathrm{t}}
$$

dimana TK merupakan total tenaga kerja, PDB adalah product domestic bruto, JU adalah jumlah unit UMKM yang ada di Indonesia; dan, Inv adalah jumlah investasi pada sektor UMKM. Sementara itu, $\alpha$ adalah konstanta, $\beta_{1,2,3}$ adalah koofisien estimasi, dan e adalah error term.

\section{HASIL ANALISIS}

Tabel 1 menggambarkan bahwa jumlah unit UMKM terbanyak di Indonesia terdapat pada tahun 2018 sebanyak 64.194057 unit, dan yang terendah pada tahun 2000 sebesar 36.784.036 unit; dengan jumlah rata rata sebanyak 49.457.421 unit. Penyerapan tenaga kerja paling banyak juga terjadi pada tahun 2018 yaitu 116.978.631 orang, dan yang terendah terjadi pada tahun 1998 sebanyak 64.313.573 orang; dengan jumlah tenaga kerja rata rata sebanyak 90.193 .012 orang.

Selanjutnya rata-rata PDB pada sektor UMKM sebesar Rp. 446,3 triliun, dengan nilai tertinggi sebesar Rp. 5.721,2 triliun pada tahun 2018 dan terendah Rp. 219.2 triliun pada tahun 1998. Nilai investasi tertinggi pada sektor UMKM terjadi pada tahun 2018 mencapai Rp. 1.675,1 triliun dan yang terendah pada tahun 1999 sebesar Rp. 106 triliun, dengan nilai rata Rp. 363,6 triliun.

Proses selanjutnya adalah pengujian stasioner masing-masing variabel penelitian. Hal ini dilakukan untuk mengantisipasi terjadinya regresi spurious atau regresi palsu (Gujarati, 2014). Jika hasil pengujian non stasioner tingkat level, maka dilanjutkan dengan uji derajat integrasi (first difference) agar variabel menjadi stasioner. Caranya adalah membandingkan nilai ADF dengan nilai kritisnya. Ketika $A D F$ value-nya lebih besar dari nilai kritisnya, maka variabel tersebut berada pada stasioner; akan tetapi jika nilai ADF variabel lebih kecil dari nilai kritisnya, maka variabel tersebut dikatakan tidak stasioner.

\section{Tabel 1. Hasil Statistik Deskriptif dari Variabel Penelitian}

\begin{tabular}{lcccc}
\hline Statistik Deskriptif & Unit & Tenaga Kerja (orang) & PDB (Rp Triliun) & Investasi (Rp. Triliun) \\
\hline Mean & 49.457 .421 & 90.193 .012 & $1.574,5$ & 363,6 \\
Median & 49.908 .229 & 86.697 .740 & $1.058,4$ & 124,0 \\
Min. & 36.784 .036 & 64.313 .573 & 219,2 & 106.0 \\
Max. & 64.194 .097 & 116.978 .631 & $5.721,2$ & $1.675,1$ \\
\hline
\end{tabular}

Sumber: Data sekunder diolah, 2020.

Tabel 2. Hasil Uji Stasioner dari Variabel Penelitian

\begin{tabular}{lcccccc}
\hline \multirow{2}{*}{ Variabel } & \multicolumn{3}{c}{ Level } & & \multicolumn{3}{c}{$I^{\text {st }}$ Difference } \\
\cline { 2 - 7 } & ADF Value & Critical Value & Hasil & ADF Value & Critical Value & Hasil \\
\hline TK & 0.4718 & -3.0123 & Non stationer & -5.7573 & 3.0206 & Stationer \\
JU & 1.0360 & -3.0123 & Non stationer & -3.7756 & -3.0206 & Stationer \\
PDB & 0.5566 & -3.0123 & Non stationer & -4.2439 & -3.0206 & Stationer \\
Inv & 3.5783 & -3.0123 & Stationer & -3.98193 & -3.0206 & Stationer \\
\hline
\end{tabular}

Sumber: Data sekunder diolah, 2020. 
Tabel 3. Hasil Uji Kointegrasi dari Variabel Penelitian

\begin{tabular}{lccc}
\hline Johansen Fisher Test & p-value & Critical Value & Prob. \\
\hline Trace Statistic & 60,9188 & 47,8563 & 0,0019 \\
Max Eigen Test & 35,6579 & 27,5843 & 0,0037 \\
\hline
\end{tabular}

Sumber: Data sekunder diolah, 2020.

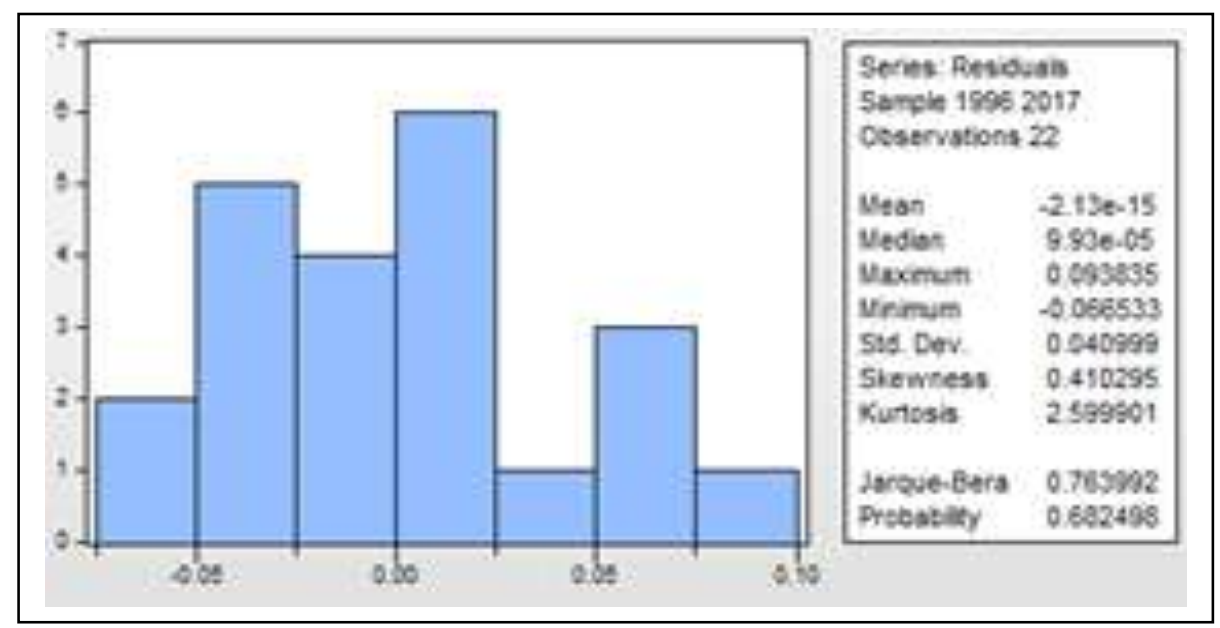

Gambar 1. Hasil Uji Normalitas

Sumber: Data sekunder diolah, 2020.

Tabel 2 menunjukkan hasil uji stasioner pada tingkat level hanya variabel investasi yang mengalami stationer; sementara variabel tenaga kerja, product domestic bruto dan jumlah unit UMKM tidak stasioner. Namun demkian, pada tingkatan first difference, seluruh variabel mengalami stationer.

Untuk melihat ada atau tidaknya jalur korelasi jangka panjang antar variabel, maka dilakukan uji kointegrasi dengan metode Johansen Test. Langkah untuk mengetahui apakah antar variabel terkointegrasi adalah dengan membandingkan nilai statistik dengan critical value $(0,05)$. Jika nilai $p$-value lebih kecil dari critical value, maka data variabel tidak terkointegrasi; sebaliknya, jika nilai $p$ value lebih besar dari critical value, maka semua variabel dinyatakan terkointegrasi.

Hasil yang ditunjukkan pada Tabel 3 menggambarkan bahwa $p$-value lebih besar dari nilai kritis, baik melalui hasil trace statistic test maupun hasil Max-Eigen test. Dengan demikian, variabel-variabel jumlah unit UMKM, tenaga kerja, product domestic bruto dan investasi sektor UMKM dinyatakan memiliki hubungan jangka panjang. Hal ini berimplikasi bahwa semakin banyak jumlah unit UMKM, investasi dan PDB, maka banyak tenaga kerja yang dapat diserap oleh UMKM di Indonesia.

\section{Hasil Uji Asumsi Klasik}

Uji asumsi klasik yang dilakukan dalam penelitian ini meliputi uji normalitas, uji heteroskedastisitas, uji autokorelasi, dan uji multikolinieritas. Hasil-hasil uji yang diperoleh diuraikan sebagai berikut.

Uji normalitas dilakukan dengan membandingkan antara nilai uji Jarque-Bera terhadap 0,05. Apabila nilai uji tersebut lebih kecil dari 0,05 berarti model penelitian tidak terdistribusi secara normal; sebaliknya, jika nilai uji Jarque-Bera lebih besar dari 0,05 berarti model terdistribusi secara normal (Nasehudin \& Gozali, 2012). Berdasarkan hasil uji normalitas seperti ditunjukkan pada 
Gambar 1, diperoleh nilai uji Jarque-Bera sebesar 0,763992 atau lebih besar dari 0,05. Hasil ini berarti bahwa model dalam penelitian ini telah memenuhi persyaratan terdistribusi secara normal.

Selanjutnya, dilakukan uji Glejser untuk mengetahui ada atau tidaknya permasalahan heteroskedasitas. Ketentuan uji yang diterapkan adalah jika nilai Prob. < 0,05 berarti terdapat permasalahan heteroskedastisitas; sebaliknya, jika nilai Prob. > 0,05 artinya tidak terdapat problem heteroskedasitas (Nasehudin \& Gozali, 2012). Hasil pengujian pada Tabel 4 menunjukkan bahwa nilai Prob. sebesar 0,3823 atau lebih besar dari 0,05. Dengan demikian bisa disimpulkan model penelitian ini bersifat non- heteroskedastisitas.

Tabel 4. Hasil Uji Heteroskedastisitas

\begin{tabular}{cccc}
\hline F Stat. & Prob & Obs $^{*} R^{2}$ & Prob \\
\hline 1,0808 & 0,3823 & 3,3581 & 0,3396 \\
\hline
\end{tabular}

Sumber: Data sekunder diolah, 2020.

Tabel 5. Hasil Uji Autokorelasi

\begin{tabular}{cccc}
\hline F Stat. & Prob & Obs $^{*} R^{2}$ & Prob \\
\hline 3,0453 & 0,0757 & 6,0656 & 0,0682 \\
\hline
\end{tabular}

Sumber: Data sekunder diolah, 2020.

Uji autokorelasi dilakukan dengan membandingkan antara nilai Prob. $O b s^{*} R^{2}$ terhadap 0,05. Apabila nilai hasil uji lebih kecil dari 0,05 berarti model mengalami autokorelasi; sebaliknya, jika nilai hasil uji lebih besar dari 0,05 berarti model tidak mengalami autokorelasi (Nasehudin \& Gozali, 2012). Hasil pengujian menggunakan aplikasi Eviews yang ditunjukkan dalam Gambar 5, menyatakan bahwa model penelitian ini tidak mengalami permasalahan autokorelasi atas masing-masing variabel. Hal ini dibuktikan dengan adanya nilai Prob. $O b s^{*} R^{2}$ yang lebih besar dari 0,05 .
Uji asumsi klasik keempat adalah uji multikolinieritas. Kriteria yang digunakan adalah coefficient correlation matrix, dimana jika nilai yang diperoleh variabel independen tidak melebihi 0,90 berarti model tidak mengalami permasalahan multikolinieritas (Nasehudin \& Gozali, 2012). Berdasarkan hasil pengujian seperti ditunjukkan dalam Tabel 6 diperoleh nilai matriks korelasi dari variabel-variabel independen tidak melebihi angka 0,90. Dengan demikian, model ini dinilai tidak mengalami multikolinieritas.

\section{Tabel 6. Hasil Uji Multikolinieritas}

\begin{tabular}{lccc}
\hline & Inv & JU & PDB \\
\hline Inv & 1,000000 & 0,809990 & 0,856092 \\
JU & 0,809990 & 1,000000 & 0,877694 \\
PDB & 0,856092 & 0,877694 & 1,000000 \\
\hline
\end{tabular}

Sumber: Data sekunder diolah, 2020.

\section{Estimasi Persamaan Jangka Pendek}

Pada bagian ini diuraikan hasil estimasi persamaan jangka pendek menggunakan error correction model (ECM), yang dirangkum dalam Tabel 7.

Hasil pengujian pada Tabel 7 menyatakan bahwa dalam jangka pendek, semua variabel mempunyai pengaruh terhadap penyerapan tenaga kerja pada sektor UMKM. Hal ini dibuktikan dimana nilai Prob. (F-stat) yang diperoleh sebesar 0,001 adalah lebih kecil dari 0,05. Selanjutnya, hasil analisis secara parsial menunjukkan variabel-variabel jumlah unit UMKM, PDB dan investasi terbukti berpengaruh terhadap penyerapan tenaga kerja, dengan nilai ketidakseimbangan sebesar $31 \%$ dari data yang digunakan.

Lebih jauh, hasil analisis pada Tabel 7 menunjukkan bahwa variabel PDB (product domestic bruto) merupakan variabel yang paling berpengaruh dan signifikan terhadap penyerapan tenaga kerja pada sektor UMKM dibandingkan dengan kedua variabel yang lain, yaitu jumlah unit UMKM dan investasi. 
Tabel 7. Hasil Estimasi Regresi Jangka Pendek

\begin{tabular}{lccc}
\hline \multicolumn{1}{c}{ Variable } & Coefficient & t-stat & Prob \\
\hline Konstanta & 0,0111 & 1,3003 & 0,2119 \\
D(JU) & 0,4546 & 2,1427 & 0,0479 \\
D(PDB) & 0,0932 & 0,0203 & 0,0003 \\
D(Inv) & $-0,0677$ & $-2,4619$ & 0,0256 \\
RES(-1) & $-0,3174$ & $-1,6799$ & 0,1124 \\
\hline $\mathrm{R}^{2}$ & 0,6408 & & \\
Adj $R^{2}$ & 0,5510 & & \\
Prob, $_{\text {F-stat })}$ & 0,0016 & & \\
\hline Sumber: Dask & & & \\
\hline
\end{tabular}

Sumber: Data sekunder diolah, 2020.

Tabel 8. Hasil Estimasi Regresi Jangka Panjang

\begin{tabular}{lccc}
\hline \multicolumn{1}{c}{ Variable } & Coefficient & t-stat & Prob \\
\hline Konstanta & 2,3559 & 1,4374 & 0,1677 \\
JU & 0,8453 & 7,4617 & 0,0000 \\
PDB & 0,0491 & 1,8286 & 0,0841 \\
Inv & $-0,0020$ & $-0,0946$ & 0,9256 \\
$\mathrm{R}^{2}$ & 0,9564 & & \\
\hline Adj $R^{2}$ & 0,9492 & & \\
Prob, $($ F-stat $)$ & 0,0000 & & \\
Constanta & 2,3559 & 1,4374 & 0,1677 \\
\hline
\end{tabular}

Sumber: Data sekunder diolah, 2020.

\section{Estimasi Persamaan Jangka Panjang}

Tahap berikutnya adalah melakukan estimasi persamaan jangka panjang menggunakan error correction model (ECM). Hasil estimasi dirangkum dalam Tabel 8.

Hasil dari pengujian untuk jangka panjang antara variabel jumlah unit UMKM, product domestic bruto dan investasi terhadap penyerapan tenaga kerja pada sektor UMKM di Indonesia seperti ditunjukkan dalam Tabel 8 menyatakan bahwa jumlah unit UMKM terbukti memiliki pengaruh secara signifikan terhadap penyerapan tenaga kerja. Hal ini dibuktikan dengan nilai Prob. (t-stat) sebesar 0,0000 yang lebih besar dari 0,05. Sebaliknya, PDB dan investasi terbukti tidak mempunyai pengaruh yang signifikan atas penyerapan tenaga kerja dalam jangka panjang, karena nilai Prob. (t-stat) yang diperoleh masingmasing variabel tersebut adalah lebih besar dari 0,05 .

\section{Pembahasan}

Hasil penelitian memaparkan bahwa dalam estimasi jangka pendek diperoleh jumlah UMKM, investasi dan PDB berpengaruh signifikan terhadap penyerapan tenaga kerja di Indonesia, baik secara parsial maupun simultan. Pengaruh dari jumlah unit UMKM serta PDB bersifat positif terhadap penyerapan tenaga kerja pada sektor UMKM. Hasil ini berarti bahwa apabila jumlah unit UMKM atau PDB mengalami kenaikan (atau penurunan), maka derajat penyerapan tenaga kerja di sektor UMKM juga mengalami kenaikan (atau penurunan). 
Sebaliknya, jumlah investasi dinyatakan berpengaruh secara negatif atas penyerapan tenaga kerja tersebut. Hasil ini berarti menunjukkan bahwa apabila jumlah investasi mengalami kenaikan, besaran penyerapan tenaga kerja di sektor UMKM di Indonesia malah mengalami penurunan. Atau, apabila jumlah investasi mengalami penurunan, maka besaran penyerapan tenaga kerja di sektor UMKM di Indonesia akan mengalami kenaikan. Kondisi ini bisa terjadi jika investasi yang dilakukan lebih mengarah pada peningkatan teknologi yang bersifat padatmodal, sehingga meminimalkan penggunaan sumber daya manusia (Widdyantoro, 2013; As'har, 2015). Disamping itu, itu kapasitas produksi yang dihasilkan UMKM belum mampu meningkatkan daya serap tenaga kerja sektor UMKM (Mulyadi et al., 2018; Mahmood, 2008; Lilyawati \& Budhi, 2014).

Lebih lanjut, hasil penelitian ini menunjukkan bahwa dalam jangka panjang hanya faktor jumlah UMKM yang memiliki pengaruh terhadap penyerapan tenaga kerja di Indonesia. Hal ini didasari jumlah investasi pada sektor UMKM yang relatif masih kurang dibandingkan dengan investasi usaha besar yang dapat menyerap tenaga kerja lebih banyak. Pada tahun 2018, investasi UMKM sebesar Rp. 1.675 triliun dengan penyerapan tenaga kerja sebanyak 116.978.631 orang; sedangkan usaha besar melakukan investasi sebesar Rp. 1.376 trilun dapat menyerap tenaga kerja sebanyak 3.619.507 orang (Kemenkop dan UKM RI, 2018). Walaupun tenaga kerja yang terserap lebih banyak sektor UMKM dibandingkan dengan usaha besar, namun jumlah investasi kedua sektor tidak terlalu jauh selisihnya.

Begitu juga terkait faktor jumlah PDB masing-masing sektor. PDB UMKM sebesar Rp. 5.721 triliun, sedangkan usaha besar sebesar Rp. 4.274 triliun. Selisih PDB antara sektor UMKM dengan usaha besar adalah sebesar Rp. 1.447 triliun dengan tingkat penyerapan tenaga kerja yang terlalu jauh berbeda. Hasil ini bertolak belakang dengan penelitian yang telah dilakukan beberapa peneliti sebelumnya (Mulyadi et al., 2018; Bustam, 2016; Widdyantoro, 2013; Sulistiawati, 2012; Setiawan, 2010). Namun demikian, semua variabel independent dalam penelitian ini secara simultan berpengaruh signifikan terhadap penyerapan tenaga kerja pada sektor UMKM di Indonesia.

\section{SIMPULAN}

Penelitian ini bertujuan menganalisis pengaruh dari jumlah unit UMKM, product domestic bruto dan investasi terhadap penyerapan tenaga kerja sektor UMKM di Indonesia. Proses analisis dilakukan menggunakan error correction model dengan model estimasi jangka pendek maupun jangka panjang. Hasil penelitian menunjukkan bahwa baik dalam jangka panjang dan pendek, jumlah UMKM merupakan faktor yang secara parsial paling berpengaruh dan signifikan terhadap penyerapan tenaga kerja sektor UMKM di Indonesia. Dalam jangka pendek, PDB terbukti juga mempengaruhi penyerapan tenaga kerja, sementara investasi diinilai tidak mempunyai pengaruh atas variabel tenaga kerja. Hasil estimasi dalam jangka panjang menyatakan bahwa PDB dan investasi tidak mempunyai pengaruh terhadap penyerapan tenaga kerja sektor UMKM di Indonesia.

Berdasarkan hasil-hasil yang diperoleh dalam penelitian ini, diharapkan pada para pengusaha UMKM untuk dapat meningkatkan kapasitasnya, terutama dalam pengembangan sumber daya manusia, melalui pelatihan soft skill yang berkenaan dengan manajemen, keuangan dan pemasaran. Bagi pemangku kebijakan dalam hal ini yang membidangi pemberdayaan UMKM maupun stakeholder lainnya, agar dapat menciptakan iklim usaha yang kondusif bagi pelaku UMKM di 
Indonesia. Hal ini tidaklah berlebihan karena mayoritas usaha masyarakat Indonesia berada dalam sektor ini.

Hasil penelitian juga membuktikan bahwa jumlah UMKM yang banyak akan dapat menciptakan lapangan pekerjaan di Indonesia. Oleh karena itu hendaknya pihak pemerintah maupun stakeholder yang terkait mendorong dan membuat kebijakan yang intinya dapat meningkatkan jumlah UMKM di Indonesia, seperti program wirausaha pemula, pemberian kredit lunak dan sebagainya. Melalui kebijakan itu, diharapkan aspekaspek investasi dan PDB pada sektor UMKM akan meningkat, yang pada akhirnya dapat mengurangi tingkat pengangguran yang ada di wilayah Indonesia.

Keterbatasan yang dinilai terdapat dalam penelitian ini yaitu bahwa data yang digunakan pada proses analisis merupakan data secara keseluruhan tanpa melihat unit usaha per sektor. Untuk itu, direkomendasikan bagi para peneliti selanjutnya untuk menggunakan data berdasarkan jenis usaha atau ragam sektor usaha pada sector UMKM di Indonesia.

\section{REFERENSI}

Abor, J., \& Quartey, P. (2010). Issues in SME development in Ghana and South Africa. International Research Journal of Finance and Economics, 39(6), 218228. Retrieved from https://www. researchgate.net/publication/270758190 _Issues_in_SME_Development_in_Gh ana_and_South_Africa.

As'har, H. A. (2015). Pola keterkaitan antar faktor yang mempengaruhi penyerapan tenaga kerja oleh sektor UMKM di Indonesia. Jurnal Ilmiah Mahasiswa FEB Universitas Brawijaya, 3(2). Retrieved from https://jimfeb.ub.ac.id/ index.php/jimfeb/article/view/1680.

BI. (2016). Metadata info dasar. Bank Indonesia. Retrieved from https://www. bi.go.id/en/iru/economic-data/metadata/
Contents/Default.aspx.

BPS. (2020). Statistik Indonesia. Badan Pusat Statistik. Retrieved from https://www. bps.go.id/publication/2020/04/29/e9011 b3155d45d70823c141f/statistikindonesia-2020.html.

Budiarto, R., Putero, S. H., Suyatna, H., Astuti, P., Saptoadi, H., Ridwan, M. M., dan Susilo, B. (2018). Pengembangan UMKM antara konseptual dan pengalaman praktis. UGM Press.

Bustam, N. H. (2016). Pengaruh jumlah unit, PDB dan investasi UMKM terhadap penyerapan tenaga kerja usaha kecil menengah di Indonesia periode 20002011. Jurnal Penelitian Sosial dan Keagamaan Kutubkhanah, 19(2), 250261. Retrieved from www.ejournal.uinsuska.ac.id.

Gujarati, D. (2014). Econometrics by example $\left(2^{\text {nd }}\right.$ ed.). Red Globe Press.

Hasanah, E. U., \& Sunyoto, D. (2014). Pengantar ilmu ekonomi makro (Teori \& soal). CAPS.

Jened, R. 2016. Teori dan kebijakan hukum investasi langsung (Direct investment). Prenada Media.

Kemenkop dan UKM RI. (2019). Statistik usaha mikro, kecil dan menengah tahun 2010-2018. Kementerian Negara KUKM. Retrieved from http://www. depkop.go.id/data-umkm.

Lilyawati \& Budhi, M. K. S. (2014). Analisis faktor yang mempengaruhi penyerapan tenaga kerja dan efisiensi usaha industri furniture Kota Denpasar. E-Jurnal Ekonomi Pembangunan, 5(8), 865-883. Retrieved from https://ojs.unud.ac.id/ index.php/eep/article/view/22235.

Mahmood, M. (2008). Labour productivity and employment in Australian manufacturing SMEs. International Entrepreneurship and Management Journal, 4(1), 51-62. doi: 10.1007/s11 365-006-0025-9.

Mulyadi, A., Hardiani, H., \& Umiyati, E. (2018). Faktor-faktor yang mempengaruhi penyerapan tenaga kerja pada sektor industri kecil di Kabupaten 
Muaro Jambi. E-Jurnal Perdagangan, Industri dan Moneter, 6(1), 35-44. Retrieved from https://online-journal. unja.ac.id/pim/article/view/4815.

Nasehudin, T. S., \& Gozali, N. (2012). Metode penelitian kuantitatif. Pustaka Setia.

Nizar, C., Hamzah, A., \& Syahnur, S. (2013). Pengaruh investasi dan tenaga kerja terhadap pertumbuhan ekonomi serta hubungannya terhadap tingkat kemiskinan di Indonesia. Jurnal Ilmu Ekonomi Pasca Sarjana Unsyiah, 1(2), 1-8. Retrieved from https://www. academia.edu/8652807/Jurnal_Ilmu_Ek onomi_PENGARUH_INVESTASI_D AN_TENAGA_KERJA_TERHADAP_ PERTUMBUHAN_EKONOMI_SERT A_HUBUNGANNYA_TERHADAP_T INGKAT_KEMISKINAN_DI_INDON ESIA.

Raselawati, A. (2011). Pengaruh perkembangan usaha kecil menengah terhadap pertumbuhan ekonomi pada sektor UKM di Indonesia. Skripsi. Jurusan Ilmu Ekonomi dan Studi Pembangunan Fakultas Ekonomi dan Bisnis UIN Syarif Hidayatullah. Retrieved from www.repository.uinjkt.ac.id.

Riani, N. Z. (2011). Identifikasi permasalahan dan kerangka pengembangan kluster UMKM sandang di Bukittinggi Sumatera Barat. TINGKAP - Jurnal Ilmiah Ilmu-ilmu Sosial Budaya \& Ekonomi, 7(1), 51-64. Retrieved from http://ejournal.unp.ac.id/index.php/ting kap/article/view/11.

Saleh, A. S., \& Ndubisi, N. O. (2006). An evaluation of SME development in Malaysia. International Review of Business Research Papers, 2(1), 1-14. Retrieved from https://researchgate.net/ publication/228869311_An_evaluation _of_SME_development_in_Malaysia.

Setiawan, A. H. (2010). Analisis penyerapan tenaga kerja pada sektor usaha kecil dan menengah (UKM), Jejak, 3(1), 3947. Retrieved from www.journal. unnes.ac.id.
Suci, Y. R. (2017). Perkembangan UMKM (Usaha mikro kecil dan menengah) di Indonesia. Jurnal Ilmiah Cano Ekonomos, 6(1), 51-58. Retrieved from https://e-journal.upp.ac.id/index.php/ Cano/article/view/1239.

Sukesti, F., \& Iriyanto, S. (2011). Pemberdayaan UKM: Meningkatkan komoditas unggulan ekspor UKM dalam rangka pengembangan ekonomi daerah (Studi pada UKM Jawa Tengah). Prosiding Seminar Nasional Ilmu Ekonomi Terapan Fakultas Ekonomi UNIMUS 2011, 86-92. Retrieved from https://jurnal.unimus. ac.id/index.php/psn12012010/article/vi ew/409.

Sulistiawati, R. (2012). Pengaruh upah minimum terhadap penyerapan tenaga kerja dan kesejahteraan masyarakat di propinsi di Indonesia. Jurnal EKSOS, 8(3), 195-211. Retrieved from www. riset.polnep.ac.id.

Syuhada, S., Tasman, A., \& Hardiani, H. (2014). Faktor-faktor yang mempengaruhi penyerapan tenaga kerja pada usaha mikro, kecil dan menengah (UMKM) di Kota Jambi. Jurnal Perspektif Pembiayaan dan Pembangunan Daerah,2(2), 93-98. doi: 10.22437/ppd.v2i2.2261.

Tyas, A. A. W. P., \& Safitri, V. I. (2014). Penguatan sektor UMKM sebagai strategi menghadapi MEA 2015. Jurnal Ekonomi Universitas Esa Unggul,5(1), 42-48. Retrieved from https://media. neliti.com/media/publications/17895ID-penguatan-sektor-umkm-sebagaistrategi-menghadapi-mea-2015.pdf.

Undang-Undang Nomor 20 Tahun 2008 tentang Usaha Mikro, Kecil dan Menengah.

Widarjono, A. (2013). Ekonometrika pengantar dan aplikasinya. UPP STIM YKPN.

Widdyantoro, A. (2013). Pengaruh PDB, investasi, dan jumlah unit usaha terhadap penyerapan tenaga kerja usaha kecil menengah di Indonesia periode 
2000-2011. Skripsi. Jurusan Ilmu Ekonomi Studi Pembangunan Fakultas Ekonomi dan Bisnis UIN Syarif Hidayatullah. Retrieved from www. repository.uinjkt.ac.id. 